\title{
Percepção de estresse e estratégias de enfrentamento em atletas de futebol religiosos
}

http://dx.doi.org/10.11606/1807-5509202000010093

\author{
Cleberson Franclin Tavares COSTA* \\ Cristiane Costa da Cunha OLIVEIRA* \\ Marlizete Maldonado VARGAS*
}

*Departamento de Pós-Graduação em Saúde e Ambiente, Universidade Tiradentes, Aracaju, SE, Brasil.

\section{Resumo}

0 objetivo deste estudo foi analisar a percepção de atletas de futebol, religiosos e não religiosos, diante de situações estressoras e as estratégias de enfrentamento utilizadas. É um estudo do tipo survey, com 81 atletas de futebol das equipes semifinalistas do Campeonato Sergipano 2014. Utilizou-se o Inventário de Fatores de Stress no Futebol (ISF) e a Escala de Modos de Enfrentamento de Problemas (EMEP). Para o tratamento estatístico dos dados foram realizadas comparações de médias de respostas entre os grupos (religiosos x não religiosos) e aplicado o teste T Student. Por intermédio dos resultados, evidenciou-se que os atletas praticantes de alguma religião perceberam as situações estressoras mais negativamente, apesar de utilizarem estratégias de enfrentamento com maior frequência. Concluiu-se que a percepção de estressores, as estratégias de enfrentamento e a frequência em que essas são utilizadas apresentam diferenças entre os grupos, sendo recomendados novos estudos para comparativo e exploração da temática.

Palavras-chave: Estresse Psicológico; Enfrentamento Religioso; Religião e Psicologia; Psicologia do Esporte.

\section{Introdução}

O esporte e a prática religiosa estão associados desde os tempos mais remotos, mesmo em diferentes civilizaçôes. Dentre os principais exemplos dessa associação estão os Jogos Olímpicos, iniciados na região da Grécia Antiga para agradecimento e adoraçáo ao divino. Os jogos contavam com diversos participantes, embora os vencedores fossem popularmente vistos como seres abençoados, predestinados pelos deuses para alcançarem tais feitos ${ }^{1}$.

Nas Américas, os Maias praticavam o juego de pelota (jogo de bola), atualmente considerado por muitos como um dos antecessores do futebol de campo. Esse jogo era praticado em um espaço construído próximo aos templos e estava relacionado a rituais religiosos, dentre os quais o sacrifício. Ao final das disputas, o corpo dos vencedores era oferecido em pira ardente aos deuses ${ }^{2}$.

Os sinais de crenças religiosas podem ser observados nas competições de futebol em vários momentos da partida: fazer o sinal da cruz ao entrar em campo, exibir frases religiosas em camisas e faixas ao comemorar um gol, ao término da partida, atribuir o sucesso ou insucesso ao divino ${ }^{3}$.

O Brasil é um país de maioria cristã, realidade que transcende o futebol, como evidenciou um estudo com grupo de atletas evangélicos denominados de "Atletas de Cristo", em Pernambuco, que investigou sintomas de ansiedade e identificou que os atletas adotavam a prática religiosa como estratégia para driblar o nervosismo, objetivando o bem-estar psicológico e melhor desempenho ${ }^{3}$.

Outro estudo, de base etnográfica, realizado com atletas brasileiros que jogavam no exterior investigou, entre outras questōes, suas religiōes, apontou que a religião era percebida de maneira positiva na vida desses atletas. As liturgias forneciam suporte mental para os jogadores, auxiliando na disciplina (geralmente as religiōes vetam idas a festas e sugerem maior cuidado com o corpo) e na organização financeira (pregando a parcimônia, baseado no pecado da luxúria $)^{4}$. 
Investigar as demandas e estratégias de enfrentamento no futebol é relevante, pois o esporte apresenta um cenário exigente e competitivo. Para tornar-se um profissional de sucesso, os atletas se submetem a intensas rotinas de treinamentos, que se iniciam ainda na adolescência. Além da dedicação quase exclusiva, os jogadores de futebol enfrentam grandes problemas, como um mercado bastante agressivo ou condições inadequadas de trabalho, sendo o sonho dos altos salários uma realidade para poucos 5 .

Diante destas e outras situações inerentes à pratica futebol profissional, o atleta é bastante exposto ao estresse, que consiste no desequilíbrio do organismo causado por estímulos intrínsecos e/ou extrínsecos ao sujeito. No esporte, o estresse pode ser compreendido como estimulador ambiental que varia de acordo com a percepção do indivíduo e pode ser interpretado como positivo (motivador) ou negativo (debilitador) $)^{6,7}$.

Estudos científicos que abordam o efeito do estresse em atletas geralmente buscam identificar fatores que estão relacionados com sua maior presença ou ausência ${ }^{8}$, investigando a relação com fatores internos e possíveis estimuladores externos?.

Para lidar com as situaçóes de estresse, e facilitar que o organismo retome o equilíbrio, o sujeito deve dispor de efetivas estratégias de enfrentamento (coping), agindo com mecanismos adaptativos ao ambiente em situaçóes adversas ${ }^{10}$. A partir de pesquisas, instrumentos foram desenvolvidos para mensurar estratégias de enfrentamento como: busca por suporte social, culpar-se, culpar outros, usar pensamentos fantasiosos, usar práticas religiosas, dentre outras ${ }^{11}$.

Por meio dos estudos pesquisados observa-se que as análises de enfrentamento de situações por meio de práticas religiosas divergem bastante. Na pesquisa de validação da Escala de Modo de Enfrentamento de Problemas (EMEP), as práticas religiosas enquanto estratégia de enfrentamento (coping religioso) foram agrupadas como "pensamentos fantasiosos". Os resultados evidenciaram que os pensamentos fantasiosos e as práticas religiosas são semelhantes devido à intenção de esquivar-se do problema ${ }^{11}$. Outros estudos apontaram que o coping religioso é uma ferramenta individual de grande potencial positivo, sendo importante para seus usuários por promover a saúde e a melhor qualidade de vida ${ }^{12,13}$.

Os estudos sobre o impacto da religião em situaçôes estressoras são escassos e não estão diretamente inseridos no contexto prático do futebol ${ }^{13,14}$. Os poucos estudos que abordam o tema não abordaram o relacionamento entre futebol, estresse e religião $0^{3,4,15}$. Por conseguinte, no atual contexto da literatura, a presente pesquisa identificou a supracitada carência e objetiva analisar a percepção de atletas de futebol - religiosos e não religiosos diante de situações estressoras e as estratégias de enfrentamento utilizadas.

\section{Método}

Estudo quantitativo, em que participaram 81 atletas do sexo masculino que integravam as quatro equipes semifinalistas do Campeonato Sergipano da primeira divisão de 2014. Cada clube dispunha de 25 atletas no elenco profissional, caracterizando a amostra inicial em 100 (25 atletas $\times 4$ clubes $=100)$, entretanto, 19 atletas não quiseram participar do estudo, fechando a amostra em 81 participantes. Os dados foram coletados entre abril e junho de 2014, período da competição estadual, coletando os dados em salas localizadas nos centros de treinamentos das respectivas equipes.

Antes da coleta de dados com os atletas, o resumo da pesquisa foi apresentado a um representante da Federação Sergipana de Futebol e aos presidentes dos clubes participantes. $\mathrm{Na}$ sequência, foi assinada uma autorização permitindo que os pesquisadores iniciassem a coleta com os atletas. No primeiro momento, foi apresentado o Termo de Consentimento Livre e Esclarecido (TCLE), ato contínuo, os atletas que aceitaram participar da pesquisa o assinaram.

Após a assinatura do TCLE, foi aplicado o Inventário de Fatores de Stress no Futebol (ISF) que averigua a percepção de estresse através da direcionalidade (positiva ou negativa), da intensidade (muito, mais ou menos ou pouco), ou da ausência (situação avaliada como neutra) ${ }^{16,17}$.

O ISF é composto por 77 itens subdivididos em sete fontes de estresse: 1)Situações de fracasso iminente ou real; 2)Situaçôes de aspectos da competição; 3)Situações de demanda física e psicológica; 4) Situações de conflito; 5)Situações de perturbação; 6)Situações de risco físico e 7) 
Situações de crítica e repreensão ${ }^{16}$.

Após preenchimento do ISF, os atletas responderam a Escala de Modo de Enfrentamento de Problemas (EMEP), para identificar as estratégias de enfrentamentos mais utilizadas. Traduzida para o português ${ }^{18}$ e posteriormente validada ${ }^{11}$, a escala inclui 45 itens agrupados em quatro fatores: 1) Enfrentamento focalizado no problema; 2) Enfrentamento focalizado na emoção; 3) Busca de práticas religiosas/Pensamentos fantasiosos e 4) Busca de suporte social. As respostas são fornecidas em escala, com escores variando entre1 (Eu nunca faço isso) a 5 (Eu sempre faço isso).

Por fim, após aplicação do EMEP, os pesquisadores perguntaram se o atleta era praticante de alguma religião, em resposta afirmativa, relatava-se qual a religiāo praticada.

Sobre o tratamento dos dados, realizou-se uma análise descritiva para mensurar o quantitativo dos atletas praticantes e dos não praticantes, e o quantitativo correspondente a cada religião. Para a análise estatística, foi utilizado o teste T Student para comparação de médias entre as avaliações aos itens do ISF e EMEP entre praticantes e não praticantes de religião. O nível de significância utilizado foi de $5 \%(p<0,05)$.

A pesquisa obedeceu às normas éticas de pesquisas realizadas com seres humanos e foi aprovado pelo Comitê de Ética em Pesquisa da Universidade Tiradentes, sob o parecer $n^{\circ} 625.388$.

\section{Resultados}

Dos 81 atletas participantes do estudo, 61 $(75,3 \%)$ se declararam praticantes de alguma religião e 20 se declararam não praticantes $(24,7 \%)$. Dos 61 praticantes, $39(63,9 \%)$ se declararam católicos e $22(36,1 \%)$ evangélicos.

Mediante comparação de médias entre as respostas atribuídas às situações estressoras, identificou-se diferença estatisticamente significativa em 10 situações correspondentes a 5 fontes de estresse (1. Situações de fracasso iminente ou real; 2. Situações de aspectos da competição; 4. Situações de conflito; 5 . Situações de perturbação; e 6. Situações de risco físico).
Em análise geral da avaliação das situações, observou-se que apenas uma foi percebida de maneira positiva por ambos os grupos (favorável ao desempenho), correspondente à situação de aspectos da competição. Por outro lado, situações de fracasso, conflito, perturbação e de risco físico, foram avaliadas como debilitadoras ao desempenho.

Evidencia-se ainda que, de nove situações avaliadas como negativas, oito tiveram mais intensidade na avaliação dos praticantes de alguma religião. A situação avaliada positivamente por ambos os grupos obteve avaliação mais positivado por não praticantes (TABELA 1).

TABELA 1 -Avaliação dos atletas sobre situações estressoras de acordo com grupos de atletas praticantes e não praticantes de alguma religião, Sergipe, 2014.

\begin{tabular}{|c|c|c|c|c|c|c|}
\hline Fonte & Situação & Grupo (n) & $\begin{array}{l}\text { Escore } \\
\text { Médio }\end{array}$ & DP & F & $\mathbf{P}$ \\
\hline \multirow{2}{*}{1} & \multirow{2}{*}{ Ter perdido de goleada } & Não Praticante (20) & $-2,05$ & 1,905 & 12,438 & 0,001 \\
\hline & & Praticante (61) & $-2,55$ & 0,946 & & \\
\hline \multirow{2}{*}{1} & \multirow{2}{*}{ Perder gol "feito" } & Não Praticante (20) & $-1,63$ & 1,832 & 7,133 & 0,009 \\
\hline & & Praticante (61) & $-1,98$ & 1,118 & & \\
\hline \multirow{2}{*}{1} & \multirow{2}{*}{ Fazer gol contra } & Não Praticante (20) & $-1,9$ & 1,651 & 5,095 & 0,027 \\
\hline & & Praticante (61) & $-2,36$ & 1,141 & & \\
\hline \multirow{2}{*}{1} & \multirow{2}{*}{ Tomar cartão amarelo } & Não Praticante (20) & $-0,75$ & 1,618 & 4,876 & 0,03 \\
\hline & & Praticante (61) & $-0,64$ & 1,081 & & \\
\hline \multirow{2}{*}{2} & \multirow{2}{*}{$\begin{array}{c}\text { Jogar contra adversários } \\
\text { desconhecidos }\end{array}$} & Não Praticante (20) & 0,7 & 1,976 & 6,49 & 0,013 \\
\hline & & Praticante (61) & 0,03 & 1,437 & & \\
\hline \multirow{2}{*}{4} & \multirow{2}{*}{$\begin{array}{l}\text { Discordância ou conflitos } \\
\text { com companheiros }\end{array}$} & Não Praticante (20) & $-1,15$ & 1,843 & 5,082 & 0,027 \\
\hline & & Praticante (61) & $-1,44$ & 1,298 & & \\
\hline
\end{tabular}

continua 
continuação

\begin{tabular}{|c|c|c|c|c|c|c|}
\hline Fonte & Situação & Grupo (n) & $\begin{array}{l}\text { Escore } \\
\text { Médio }\end{array}$ & $\mathrm{DP}$ & $\mathrm{F}$ & $\mathrm{P}$ \\
\hline \multirow{2}{*}{5} & \multirow{2}{*}{$\begin{array}{l}\text { Comportamento de jorna- } \\
\text { listas antes do jogo }\end{array}$} & Não Praticante (20) & 0,1 & 1,483 & 4,584 & 0,035 \\
\hline & & Praticante (61) & $-0,16$ & 0,86 & & \\
\hline \multirow{2}{*}{5} & \multirow{2}{*}{ Conflito com os familiares } & Não Praticante (20) & $-1,95$ & 2,012 & 6,7 & 0,011 \\
\hline & & Praticante (61) & $-2,08$ & 1,229 & & \\
\hline \multirow{2}{*}{5} & \multirow{2}{*}{$\begin{array}{c}\text { Estar com o salário } \\
\text { atrasado }\end{array}$} & Não Praticante (20) & $-2,05$ & 1,669 & 6,75 & 0,011 \\
\hline & & Praticante (61) & $-2,46$ & 1,089 & & \\
\hline \multirow{2}{*}{6} & \multirow{2}{*}{ Jogar em campo ruim } & Não Praticante (20) & $-1,85$ & 1,755 & 12,407 & 0,001 \\
\hline & & Praticante (61) & $-2,4$ & 0,978 & & \\
\hline
\end{tabular}

Sobre as estratégias de enfrentamento, cinco itens apresentaram significância: duas focadas no problema, duas focadas na emoção e uma relacionada a práticas religiosas/pensamentos fantasiosos. As estratégias foram adotadas com mais frequência pelos atletas praticantes de alguma religião (TABELA 2), exceto "Desconto em outras pessoas".

Mediante os resultados, observou-se, também, que os praticantes apresentaram maior repertório de estratégias de enfrentamento, especialmente as estratégias focadas no problema e de práticas religiosas/pensamentos fantasioso.

TABELA 2 -Avaliação dos atletas sobre a frequência de utilização de estratégias de enfrentamento de acordo com grupos de atletas praticantes e não praticantes de alguma religião, Sergipe, 2014.

Fonte: Elaborada pelos autores.

\begin{tabular}{|c|c|c|c|c|c|}
\hline $\begin{array}{l}\text { Estratégia de Enfrenta- } \\
\text { mento }\end{array}$ & Grupo (n) & $\begin{array}{l}\text { Escore } \\
\text { Médio }\end{array}$ & DP & $\mathbf{F}$ & $\mathbf{P}$ \\
\hline \multirow{2}{*}{$\begin{array}{l}\text { Levar em conta o lado } \\
\text { positivo das coisas }\end{array}$} & Não Praticante (20) & 3,9 & 1,518 & 12,487 & 0,001 \\
\hline & Praticante (61) & 4.1 & 0,978 & & \\
\hline \multirow{2}{*}{$\begin{array}{l}\text { Insistir e lutar pelo que } \\
\text { quer }\end{array}$} & Não Praticante (20) & 4,45 & 1,146 & 9,043 & 0,004 \\
\hline & Praticante (61) & 4,79 & 0,635 & & \\
\hline Brigar consigo mesmo/ & Não Praticante (20) & 3,7 & 1,38 & 6,562 & 0,012 \\
\hline mesmo o que deve fazer & Praticante (61) & 3,85 & 1,03 & & \\
\hline \multirow{2}{*}{$\begin{array}{l}\text { Descontar em outras } \\
\text { pessoas }\end{array}$} & Não Praticante (20) & 1,63 & 1,116 & 4,228 & 0,043 \\
\hline & Praticante (61) & 1,52 & 0,721 & & \\
\hline \multirow{2}{*}{$\begin{array}{l}\text { Sonhar ou imaginar um } \\
\text { tempo melhor do que } \\
\text { aquele em que está }\end{array}$} & Não Praticante (20) & 4,1 & 1,071 & 17,251 & 0,001 \\
\hline & Praticante (61) & 4,7 & 0,587 & & \\
\hline
\end{tabular}

\section{Discussão}

A maioria evidenciada de atletas cristãos, reflete a atual realidade da sociedade brasileira apontada no último censo do Instituto Brasileiro de Geografia e Estatística (IBGE), em que 92\% dos brasileiros são praticantes de alguma religião, sendo a maioria cristã $(86,8 \%)$, católicos $(64,6 \%)$ ou evangélicos $(22,2 \%)^{19}$. A religião é importante para o comportamento humano pois oferece prerrogativas para o sucesso nesta vida ou além. O catolicismo sempre exerceu influência na sociedade brasileira, contribuindo desde questôes arquitetônicas, até normas sociais e comportamentos regidos pelos princípios desta religião ${ }^{20}$.

O grupo de atletas religiosos percebeu de forma mais negativa a maioria dos fatores de estresse. Similarmente às evidências encontradas neste estudo, pesquisa realizada com 73 futebolistas nas fases pré-competitiva e competitiva identificou que o uso de estratégias baseadas em práticas religiosas e pensamentos fantasiosos apresentaram relação com índices de burnout mais elevados, prevalência de sentimentos negativos e reduzido senso de realização profissional ${ }^{21}$. 
Por outro lado, os resultados desta pesquisa divergem de outros realizados com atletas de futebol. Uma investigação com os Atletas de Cristo (grupo de atletas evangélicos) de duas equipes de Pernambuco evidenciou que os rituais religiosos auxiliavam os atletas no controle da ansiedade, contribuindo para melhor performance ${ }^{3}$. Outro estudo, realizado com futebolistas brasileiros que jogavam no exterior, constatou que a crença em Deus (seguida da adesão a práticas de uma religião) foi considerada fundamental para melhorar desempenho profissional ${ }^{4}$.

Um estudo realizado com atletas de equipes colombianas sub-17 também evidenciou a relação entre prática religiosa e bem-estar psicológico. Os autores identificaram que, em ambas equipes, os atletas adotavam o tipo de enfrentamento religioso como um dos principais. Dentre as práticas mais adotadas estavam as orações, que promoviam um conforto na espera de solução de problemas, evitando o estresse e sentimentos negativos ${ }^{22}$.

Ampliando a discussão e baseando-se em estudos com profissionais de outras áreas, evidenciou-se que o aspecto religioso também é compreendido como um tipo de enfrentamento que exerce influência negativa na qualidade de vida do sujeito ${ }^{23,24}$. Esta influência negativa ocorre quando o pensamento religioso conduz o sujeito a sentir-se castigado por Deus e atribuir o significado da situação adversa a uma punição divina ${ }^{24}$. Deste modo, a maneira de interpretar a situação adversa como situações de punição divina e imutável pode explicar a causa da percepção mais negativa dos atletas praticantes. Se o atleta percebe uma situação como imutável, esta pode provocar sensação de impotência e queda no rendimento profissional.

Apesar da percepção predominantemente negativa das situaçôes, os atletas religiosos praticantes apresentaram maior frequência e variedade de estratégias de enfrentamento, principalmente as que mantém foco no problema e em base religiosa/ pensamento fantasioso. Os resultados são similares aos achados de um levantamento realizado com 172 atletas de futebol de base, onde identificou-se que as estratégias focadas no problema e na prática religiosa/ pensamento fantasioso foram as mais utilizadas. Os autores destacaram a influência da religião sobre o comportamento dos futebolistas, que vai desde as comemorações até à alimentação e ao cuidado com o corpo, variando de acordo com os dogmas e rituais de cada religião. A conclusão deste estudo concluíram reforça que a identificação das estratégias de coping adotadas pelos atletas é importante para que estes sejam orientados a utilizar estratégias focadas no problema e no suporte social, considerando como facilitadoras na resolução de problemas ${ }^{25}$.

As práticas religiosas dos atletas e a influência destas no seu rendimento e bem estar, foram consideradas relevantes pois sua utilização pode representar um suporte positivo, desde que o direcionamento perceptivo esteja voltado para aliviar sentimentos negativos. Por outro lado, o uso de práticas religiosas como estratégias de coping pode gerar conformismo e queda do rendimento do atleta, resultando no aumento do estresse negativo.

É importante salientar que a prática religiosa é particular e de direito dos atletas, e que, trabalhar com a variedade de enfrentamentos de base religiosa pode levar o indivíduo a facilitar ou dificultar sua adaptação em situações adversas. Assim, compete aos profissionais que trabalham com os atletas, oferecer suporte técnico para a escolha da melhor forma de enfrentar as situações estressores que podem afetar o rendimento individual e coletivo das equipes em competições.

Conclui-se que a avaliação de situações de estresse no futebol e as estratégias de enfrentamento alteram mediante a variável 'religião'. Evidenciou-se diferenças entre essas avaliaçõos e uso de estratégias de enfrentamento em grupos de atletas praticantes de alguma religião e não praticantes. Ressalta-se que os resultados trazem ineditismo na pesquisa entre percepção de estresse em atletas de futebol, e sugerese novos estudos para comparação e discussão de resultados em outras regiōes do Brasil, uma vez que na literatura o tema é emergente e controverso.

\section{Abstract}

Perception of stress and coping in religious soccer athletes

This study aims to analyse the perception of religious and nonreligious soccer players before stressful situations, as well as coping strategies. It is a survey-type study, with 81 soccer players of Sergipe's Championship 2014's semi-finalist teams. We used the Inventory of Stress Factors in Football (ISF) and 
the Confronting Problems Modes Scale (EMEP).To statistically analyse data we compared answers between groups (religious $x$ nonreligious) and applied the Student T test. Through the results obtained, we observed that religious athletes perceived stressful situations more negatively, despite using coping strategies more often. We concluded that the perception of stress factors, coping strategies and how often these are used differ between the groups, and recommend further studies to compare and deeply explore this thematic.

Kerwords: Psychological Stress; Religious Coping; Religion and Psychology; Sports Psychology.

\section{Referências}

1. Machado RPT. Entre o mito e a história: gênese e desenvolvimento das manifestaçôes atléticas na Grécia antiga [Tese]. São Paulo (SP): Universidade de São Paulo, Escola de Educação Física e Esporte; 2010.

2. Londoño FT. No princípio da história, era um jogo de bola. jogo, poder e religiáo entre os maias. Revista de Estudos da Religiáo. 2015;15:111-125.

3. Paes RVDC. The Athletes of Christ in football and the symptoms of anxiety. Paralellus. 2013;4:95-106.

4. Rial C. Rodar: a circulaçáo dos jogadores de futebol brasileiros no exterior. Horizontes Antropológicos. 2008;14:21-65.

5. Soares AJG, Melo LBSD, Costa FRD, Bartholo TL, Bento JO. Jogadores de futebol no Brasil: mercado, formação de atletas e escola. Revista Brasileira de Ciências do Esporte. 2011;33:305-21.

6. Santos AM,Castro JJD. Stress. Análise Psicológica. 1998;16:675-690.

7. Verardi CEL, Miyazaki MCDOS, Nagamine KK, Lobo APDS, Domingos NAM. Sport, stress and burnout. Estudos de Psicologia. 2012;29:305-313.

8. Simim MADM, Costa VT, Samulski DM, Ferreira RM. Análise do estresse em atletas de futebol para amputados. Revista da Educação Física/UEM. 2010;21:237-244.

9. Mortatti AL, Coelho AAC, Costa EC. Monitoramento da carga interna de treinamento, tolerância ao estresse e ocorrência de infecçóes em jovens atletas de futebol. Revista da Educação Física/UEM. 2014;25(4):629-638.

10. Antoniazzi AS, Dell'aglio DD, Bandeira DR. O conceito de coping: uma revisáo teórica. Estudos de Psicologia. 1998;3(2):273-294.

11. Seidl EMF, Tróccoli BT, Zannon CMLC. Análise fatorial de uma medida de estratégias de enfrentamento. Psicologia: teoria e pesquisa. 2001;17:225-234.

12. Panzini RG, Bandeira DR. Escala de coping religioso-espiritual (Escala CRE): elaboração e validaçáo de construto. Psicologia em Estudo. 2005;10:507-516.

13. Panzini RG, Bandeira DR. Coping (enfrentamento) religioso/espiritual. Revista de Psiquiatria Clínica. 2007;34:126135.

14. Silveira KA, Enumo SRF, Batista EP. Stress indicators and coping strategies for teachers of multi grade teaching. Psicologia Escolar e Educacional.2014;18:457-465.

15. Rial C. Banal religiosity: Brazilian athletes as new missionaries of the neo-Pentecostal diaspora. Virtual Brazilian Anthropology. 2012;9:128-159.

16. Brandão MRF. Fatores de Stress em jogadores de futebol [Tese]. Campinas (SP): Universidade Estadual de Campinas, Escola de Educaçáo Física; 2000.

17. Sanches AB, Casal HMV, Brandão MRF. Fatores de estresse no futebol. Lecturas: Educación física y deportes. 2004;73:8.

18. Gimenes MGG, Queiroz B. As diferentes fases de enfrentamento durante o primeiro ano após a mastectomia. In:Gimenes MMG, Fávero MH, organizadores. A mulher e o câncer. Campinas: Editorial Psy; 1997.p.171-195.

19. Instituto Brasileiro de Geografia e Estatística. Censo demográfico: 2010: características gerais da população, religião e pessoas com deficiência. Disponível em: http://biblioteca.ibge.gov.br/visualizacao/periodicos/94/cd_2010_religiao_deficiencia.pdf.

20. Gonçalves A. A Igreja Católica: Patrimônio e Identidade. Interfaces Científicas -Humanas e Sociais. 2013;1(3):33-40.

21. Verardi CEL, Santos AB, Nagamine KK, Carvalho TD, Miyazaki MCDOS. Burnout and coping among football players: before and during the tournament. Revista Brasileira de Medicina do Esporte. 2014;20(4):272-275.

22. Montes Durango JA, Restrepo Montoya JG. Diferencias de las estrategias de afrontamiento del estrés precompetencia de los equipos categoría" Primera c" de la Fundación Camilo Zúńiga y las divisiones inferiores del Club Atlético Na- 
cional [Monografia] Medellín: Universidad de Antioquia, Facultad de Ciencias Sociales y Humanas; 2015.

23. Linhares V, Meneses RF, Pais-Ribeiro J, et al. Preditores da qualidade de vida na epilepsia. Psicologia, Saúde \& Doenças. 2014;15:61-77.

24. Nuñes P, Enríquez D, Irarrázaval ME. La espiritualidad en el paciente oncológico: una forma de nutrir la esperanza y fomentar un afrontamiento positivo a la enfermedad. Ajayu. 2011;10:84-100.

25. Bagni G, Machado AA, Barbosa CG, Verzani RH, Morão KG. Estratégias de enfrentamento de problemas em jovens atletas: um estudo através do EMEP. Coleção Pesquisa em Educação Física. 2013;12:63-70.

ENDEREÇO DE CORRESPONDÊNCIA: Cleberson Franclin Tavares Costa Avenida Murilo Dantas, Sala 2, Bloco F - Farolândia Aracaju - SE - BRASIL CEP: 49032-490 E-mail: costacleberson90@gmail.com; cleberson_tyto@hotmail.com
Submetido: 31/08/2016

Revisado: 28/02/2018

Aceito: 26/09/2018 